\title{
A sharp generalization on cone b-metric space over Banach algebra
}

\author{
Huaping Huang ${ }^{a}, *$, Stojan Radenović ${ }^{b}$, Guantie Deng ${ }^{a}$ \\ ${ }^{a}$ School of Mathematical Sciences, Beijing Normal University, Laboratory of Mathematics and Complex Systems, Ministry of Education, \\ Beijing, 100875, China. \\ ${ }^{b}$ Faculty of Mechanical Engineering, University of Belgrade, Kraljice Marije 16, 11120, Beograd, Serbia.
}

Communicated by Y. J. Cho

\begin{abstract}
The aim of this paper is to generalize a famous result for Banach-type contractive mapping from $\rho(k) \in\left[0, \frac{1}{s}\right)$ to $\rho(k) \in[0,1)$ in cone b-metric space over Banach algebra with coefficient $s \geqslant 1$, where $\rho(k)$ is the spectral radius of the generalized Lipschitz constant $k$. Moreover, some similar generalizations for the contractive constant $k$ from $k \in\left[0, \frac{1}{s}\right)$ to $k \in[0,1)$ in cone $b$-metric space and in b-metric space are also obtained. In addition, two examples are given to illustrate that our generalizations are in fact real generalizations. (C)2017 All rights reserved.
\end{abstract}

Keywords: Cone b-metric space over Banach algebra, fixed point, c-sequence, iterative sequence. 2010 MSC: 47H10, 54H25.

\section{Introduction and preliminaries}

Since Bakhtin [1] or Czerwik [4] introduced b-metric space, also called metric type space by some authors, as a large generalization of metric space, people have paid close attention to fixed point results in such spaces for many years. Recently, Jovanović et al. [10] proved Banach-type version of a fixed point result (see [2]) for contractive mapping including the contractive constant $k \in\left[0, \frac{1}{s}\right)$ in $b$-metric space with coefficient $s \geqslant 1$. Subsequently, Huang and $\mathrm{Xu}$ [8] expanded the work of [10] into cone b-metric space with coefficient $s \geqslant 1$, where the contractive constant $k$ also satisfies $k \in\left[0, \frac{1}{s}\right)$. Later on, Huang and Radenović [7] gave a further generalization from cone b-metric space with coefficient $s \geqslant 1$ to cone b-metric space over Banach algebra with the same coefficient. They considered the Banach-type version of a fixed point result with the generalized Lipschitz constant $k$ satisfying $\rho(k) \in\left[0, \frac{1}{s}\right)$, where $\rho(k)$ is the spectral radius of $k$. So far, there have been some open questions whether the result in $b$-metric space or in cone b-metric space is true for $k \in[0,1)$, and whether the result in cone b-metric space over Banach algebra is true for $\rho(k) \in[0,1)$. In this paper, by using a new method of proof, we prove that the answers to the above questions are positive.

\footnotetext{
*Corresponding author Deng)

Email addresses: mathhhp@163.com (Huaping Huang), radens@beotel.net (Stojan Radenović), denggt@bnu.edu.cn (Guantie doi:10.22436/jnsa.010.02.09
} 
Definition 1.1 ([1,4]). Let $X$ be a (nonempty) set and $s \geqslant 1$ be a given real number. A function $d: X \times X \rightarrow$ $[0, \infty)$ is called a b-metric on $X$, if for all $x, y, z \in X$ the following conditions hold:

(b1) $d(x, y)=0$ iff $x=y$;

(b2) $d(x, y)=d(y, x)$;

(b3) $d(x, z) \leqslant s[d(x, y)+d(y, z)]$.

In this case, the pair $(X, d)$ is called a $b$-metric space.

For some concepts such as b-convergence, b-Cauchy sequence and b-completeness in the setting of b-metric spaces, the reader refers to [10, 13, 15].

In the following example we correct some errors from several papers (see [3, 12-16]) for b-metric space with the false coefficient $s=2^{\frac{1}{p}}$. As a matter of fact, its correct coefficient should be $s=2^{\frac{1}{p}-1}$.

Example 1.2. The set $l_{p}(\mathbb{R})$ with $0<p<1$, where

$$
l_{\mathfrak{p}}(\mathbb{R}):=\left\{\left.\left\{x_{n}\right\} \subseteq \mathbb{R}\left|\sum_{n=1}^{\infty}\right| x_{n}\right|^{p}<\infty\right\},
$$

together with the mapping $d: l_{p}(\mathbb{R}) \times l_{p}(\mathbb{R}) \rightarrow[0, \infty)$ defined by

$$
d(x, y)=\left(\sum_{n=1}^{\infty}\left|x_{n}-y_{n}\right|^{p}\right)^{\frac{1}{p}}
$$

for each $x=\left\{x_{n}\right\}, y=\left\{y_{n}\right\} \in l_{p}(\mathbb{R})$ is a $b$-metric space with coefficient $s=2^{\frac{1}{p}-1}$.

In fact, we only need to prove that condition (b3) in Definition 1.1 is satisfied. To this end, let $x=$ $\left\{x_{n}\right\}, y=\left\{y_{n}\right\}, z=\left\{z_{n}\right\} \in l_{p}(\mathbb{R})$, we shall show that

$$
\left(\sum_{n=1}^{\infty}\left|x_{n}-z_{n}\right|^{p}\right)^{\frac{1}{p}} \leqslant 2^{\frac{1}{p}-1}\left[\left(\sum_{n=1}^{\infty}\left|x_{n}-y_{n}\right|^{p}\right)^{\frac{1}{p}}+\left(\sum_{n=1}^{\infty}\left|y_{n}-z_{n}\right|^{p}\right)^{\frac{1}{p}}\right] .
$$

Denote $a_{n}=x_{n}-y_{n}, b_{n}=y_{n}-z_{n}$, then $x_{n}-z_{n}=a_{n}+b_{n}$, so (1.1) becomes

$$
\left(\sum_{n=1}^{\infty}\left|a_{n}+b_{n}\right|^{p}\right)^{\frac{1}{p}} \leqslant 2^{\frac{1}{p}-1}\left[\left(\sum_{n=1}^{\infty}\left|a_{n}\right|^{p}\right)^{\frac{1}{p}}+\left(\sum_{n=1}^{\infty}\left|b_{n}\right|^{p}\right)^{\frac{1}{p}}\right] .
$$

In order to prove (1.2), we notice that the following inequalities:

$$
\begin{array}{ll}
(a+b)^{p} \leqslant a^{p}+b^{p}, & (a, b \geqslant 0,0<p \leqslant 1), \\
(a+b)^{p} \leqslant 2^{p-1}\left(a^{p}+b^{p}\right), \quad(a, b \geqslant 0, p \geqslant 1),
\end{array}
$$

then

$$
\begin{aligned}
& \left(\sum_{n=1}^{\infty}\left|a_{n}+b_{n}\right|^{p}\right)^{\frac{1}{p}} \leqslant\left[\sum_{n=1}^{\infty}\left(\left|a_{n}\right|+\left|b_{n}\right|\right)^{p}\right]^{\frac{1}{p}} \leqslant\left[\sum_{n=1}^{\infty}\left(\left|a_{n}\right|^{p}+\left|b_{n}\right|^{p}\right)\right]^{\frac{1}{p}} \\
& =\left(\sum_{n=1}^{\infty}\left|a_{n}\right|^{p}+\sum_{n=1}^{\infty}\left|b_{n}\right|^{p}\right)^{\frac{1}{p}} \leqslant 2^{\frac{1}{p}-1}\left[\left(\sum_{n=1}^{\infty}\left|a_{n}\right|^{p}\right)^{\frac{1}{p}}+\left(\sum_{n=1}^{\infty}\left|b_{n}\right|^{p}\right)^{\frac{1}{p}}\right] .
\end{aligned}
$$


Let $\mathbb{A}$ be a real Banach algebra, $\|\cdot\|$ be its norm and $\theta$ be its zero element. A nonempty closed subset $\mathrm{P}$ of $\mathbb{A}$ is called a cone, if $\mathrm{P}^{2}=\mathrm{P} \cap \mathrm{P} \subset \mathrm{P}, \mathrm{P} \cap(-\mathrm{P})=\{\theta\}$ and $\lambda \mathrm{P}+\mu \mathrm{P} \subset \mathrm{P}$ for all $\lambda, \mu \geqslant 0$. We denote int $\mathrm{P}$ as the interior of $P$. If intP $\neq \emptyset$, then $P$ is said to be a solid cone. Define a partial ordering $\preceq$ with respect to $\mathrm{P}$ by $u \preceq v$, iff $v-u \in P$. Define $u \ll v$, iff $v-u \in$ intP.

In the sequel, unless otherwise specified, we always suppose that $\mathbb{A}$ is a real Banach algebra with a unit $e, \mathrm{P}$ is a solid cone in $\mathbb{A}$, and " $\preceq "$ and " $\ll "$ are partial orderings with respect to $\mathrm{P}$.

Definition 1.3 ([7]). Let $X$ be a (nonempty) set, $s \geqslant 1$ be a constant and $\mathbb{A}$ be a Banach algebra. Suppose that a mapping $d: X \times X \rightarrow \mathbb{A}$ satisfies for all $x, y, z \in X$,

(d1) $\theta \preceq d(x, y)$ and $d(x, y)=\theta$, iff $x=y$;

(d2) $d(x, y)=d(y, x)$;

(d3) $d(x, z) \preceq s[d(x, y)+d(y, z)]$.

Then $d$ is called a cone b-metric on $X$, and $(X, d)$ is called a cone b-metric space over Banach algebra.

For some examples on cone b-metric space over Banach algebra, the reader refers to [6, 7].

Definition $1.4([6])$. A sequence $\left\{u_{n}\right\}$ in a solid cone $P$ is said to be a $c$-sequence, if for each $c \gg \theta$, there exists a natural number $\mathrm{N}$ such that $u_{n} \ll c$ for all $n>N$.

Definition 1.5. Let $(X, d)$ be a cone b-metric space over Banach algebra and $\left\{x_{n}\right\}$ a sequence in $X$. We say that

(i) $\left\{x_{n}\right\}$ b-converges to $x \in X$, if $\left\{d\left(x_{n}, x\right)\right\}$ is a c-sequence;

(ii) $\left\{x_{n}\right\}$ is a b-Cauchy sequence, if $\left\{d\left(x_{n}, x_{m}\right)\right\}$ is a c-sequence for $n, m$;

(iii) $(X, d)$ is b-complete, if every b-Cauchy sequence in $X$ is b-convergent.

Lemma 1.6 ([7]). Let $\left\{u_{n}\right\}$ and $\left\{v_{n}\right\}$ be two c-sequences in a solid cone $P$. If $\alpha, \beta \in P$ are two arbitrarily given vectors, then $\left\{\alpha u_{n}+\beta v_{n}\right\}$ is a c-sequence.

Lemma 1.7 ([9]). If $u \preceq v$ and $v \ll w$, then $u \ll w$.

Lemma 1.8 ([6]). Let $\mathbb{A}$ be a Banach algebra with a unit e, then the spectral radius $\rho(k)$ of $k \in \mathbb{A}$ holds

$$
\rho(k)=\lim _{n \rightarrow \infty}\left\|k^{n}\right\|^{\frac{1}{n}}=\inf \left\|k^{n}\right\|^{\frac{1}{n}} .
$$

If $\rho(k)<1$, then $e-k$ is invertible in $\mathbb{A}$, moreover, $(e-k)^{-1}=\sum_{i=0}^{\infty} k^{i}$.

Lemma 1.9 ([6]). Let $\mathbb{A}$ be a Banach algebra with a unit e. Let $\mathrm{k} \in \mathbb{A}$ and $\rho(k)<1$. Then $\left\{\mathrm{k}^{\mathrm{n}}\right\}$ is a c-sequence.

\section{Main results}

Theorem 2.1. Let $(\mathrm{X}, \mathrm{d})$ be a $\mathrm{b}$-complete cone $\mathrm{b}$-metric space over Banach algebra with coefficient $\mathrm{s} \geqslant 1$. Suppose that $\mathrm{T}: \mathrm{X} \rightarrow \mathrm{X}$ is a mapping such that for all $\mathrm{x}, \mathrm{y} \in \mathrm{X}$ it holds:

$$
d(T x, T y) \preceq k d(x, y),
$$

where $\mathrm{k} \in \mathrm{P}$ is a generalized Lipschitz constant with $\rho(\mathrm{k})<1$. Then $\mathrm{T}$ has a unique fixed point in $\mathrm{X}$. And for any $x \in X$, the iterative sequence $\left\{T^{n} x\right\}(n \in \mathbb{N})$ b-converges to the fixed point.

Proof. Let $x_{0} \in X$ and $x_{n+1}=T x_{n}$ for all $n \in \mathbb{N}$. We divide the proof into three cases. 
Case 1: Let $\rho(k) \in\left[0, \frac{1}{s}\right)(s>1)$. By (2.1), we have

$$
\begin{aligned}
\mathrm{d}\left(x_{n}, x_{n+1}\right) & =d\left(T x_{n-1}, T x_{n}\right) \\
& \preceq k d\left(x_{n-1}, x_{n}\right) \\
& =k d\left(T x_{n-2}, T x_{n-1}\right) \\
& \preceq k^{2} d\left(x_{n-2}, x_{n-1}\right) \\
& \vdots \\
& \preceq k^{n} d\left(x_{0}, x_{1}\right) .
\end{aligned}
$$

In view of $\rho(k)<\frac{1}{s}$, then $\rho(s k)=s \rho(k)<1$, so by Lemma 1.8, we get that $e-s k$ is invertible and $(e-s k)^{-1}=\sum_{i=0}^{\infty}(s k)^{i}$. Thus for any $n>m$, it follows that

$$
\begin{aligned}
& d\left(x_{m}, x_{n}\right) \preceq s\left[d\left(x_{m}, x_{m+1}\right)+d\left(x_{m+1}, x_{n}\right)\right] \\
& \preceq \mathrm{sd}\left(x_{\mathrm{m}}, x_{\mathrm{m}+1}\right)+\mathrm{s}^{2}\left[\mathrm{~d}\left(\mathrm{x}_{\mathrm{m}+1}, x_{\mathrm{m}+2}\right)+\mathrm{d}\left(x_{\mathrm{m}+2}, x_{n}\right)\right] \\
& \preceq \mathrm{sd}\left(x_{\mathrm{m}}, x_{\mathrm{m}+1}\right)+\mathrm{s}^{2} \mathrm{~d}\left(x_{\mathrm{m}+1}, x_{\mathrm{m}+2}\right)+\mathrm{s}^{3}\left[\mathrm{~d}\left(x_{\mathrm{m}+2}, x_{\mathrm{m}+3}\right)+\mathrm{d}\left(x_{\mathrm{m}+3}, x_{n}\right)\right] \\
& \preceq s d\left(x_{m}, x_{m+1}\right)+s^{2} d\left(x_{m+1}, x_{m+2}\right)+s^{3} d\left(x_{m+2}, x_{m+3}\right) \\
& +\cdots+s^{n-m-1} d\left(x_{n-2}, x_{n-1}\right)+s^{n-m-1} d\left(x_{n-1}, x_{n}\right) \\
& \preceq s k^{m} d\left(x_{0}, x_{1}\right)+s^{2} k^{m+1} d\left(x_{0}, x_{1}\right)+s^{3} k^{m+2} d\left(x_{0}, x_{1}\right) \\
& +\cdots+s^{n-m-1} k^{n-2} d\left(x_{0}, x_{1}\right)+s^{n-m-1} k^{n-1} d\left(x_{0}, x_{1}\right) \\
& \preceq s k^{m}\left(e+s k+s^{2} k^{2}+\cdots+s^{n-m-2} k^{n-m-2}+s^{n-m-1} k^{n-m-1}\right) d\left(x_{0}, x_{1}\right) \\
& \preceq s k^{m}\left[\sum_{i=0}^{\infty}(s k)^{i}\right] d\left(x_{0}, x_{1}\right) \\
& =\mathrm{sk}^{\mathrm{m}}(e-s \mathrm{k})^{-1} \mathrm{~d}\left(\mathrm{x}_{0}, \mathrm{x}_{1}\right) \text {. }
\end{aligned}
$$

Note that $\rho(k)<\frac{1}{s}<1$ and Lemma 1.9, it is easy to see that $\left\{k^{m}\right\}$ is a c-sequence. Therefore, by using Lemma 1.6 and Lemma 1.7, we claim that $\left\{x_{n}\right\}$ is a b-Cauchy sequence. Since $(X, d)$ is b-complete, then there exists $x^{*} \in X$ such that $\left\{x_{n}\right\} b$-converges to $x^{*}$.

Next, let us show that $x^{*}$ is a fixed point of T. Indeed, by (2.1), we have

$$
d\left(x_{n+1}, T x^{*}\right) \preceq k d\left(x_{n}, x^{*}\right) .
$$

Since $\left\{d\left(x_{n}, x^{*}\right)\right\}$ is a $c$-sequence, then by Lemma 1.6 , it is not hard to verify that $\left\{k d\left(x_{n}, x^{*}\right)\right\}$ is a csequence. Hence, by Lemma 1.7, (2.2) implies that $\left\{d\left(x_{n+1}, T x^{*}\right)\right\}$ is also a c-sequence, which means that $\left\{x_{n}\right\}$ b-converges to $T x^{*}$. By the uniqueness of limit of a b-convergent sequence, we get $T x^{*}=x^{*}$. That is to say, $x^{*}$ is a fixed point of $\mathrm{T}$.

Further, $x^{*}$ is the unique fixed point of T. Actually, assume that there is another fixed point $y^{*}$, then by (2.1), it is obvious that

$$
d\left(x^{*}, y^{*}\right)=d\left(T x^{*}, T y^{*}\right) \preceq k d\left(x^{*}, y^{*}\right) \preceq k^{2} d\left(x^{*}, y^{*}\right) \preceq \cdots \preceq k^{n} d\left(x^{*}, y^{*}\right) .
$$

Now that $\left\{k^{n}\right\}$ is a $c$-sequence, then by Lemma 1.6 and Lemma 1.7 , we obtain $d\left(x^{*}, y^{*}\right)=\theta$. This leads to $x^{*}=y^{*}$.

Case 2: Let $\rho(k) \in\left[\frac{1}{s}, 1\right)(s>1)$. In this case, we have $[\rho(k)]^{n} \rightarrow 0$ as $n \rightarrow \infty$, then there is $n_{0} \in \mathbb{N}$ such that $[\rho(k)]^{n_{0}}<\frac{1}{s}$. Notice that

$$
\rho\left(k^{n_{0}}\right)=\lim _{n \rightarrow \infty}\left\|\left(k^{n_{0}}\right)^{n}\right\|^{\frac{1}{n}}
$$




$$
\begin{aligned}
& =\lim _{n \rightarrow \infty}\|\underbrace{k^{n} \cdots \cdots k^{n}}_{n_{0} \text { terms }}\|^{\frac{1}{n}} \\
& \leqslant \lim _{n \rightarrow \infty}(\underbrace{\left\|k^{n}\right\| \cdots \cdots\left\|k^{n}\right\|}_{n_{0} \text { terms }})^{\frac{1}{n}} \\
& =(\underbrace{\left.\lim _{n \rightarrow \infty}\left\|k^{n}\right\|^{\frac{1}{n}}\right) \cdots \cdots\left(\lim _{n \rightarrow \infty}\left\|k^{n}\right\|^{\frac{1}{n}}\right.}_{n_{0} \text { terms }}) \\
& =[\rho(k)]^{n_{0}} \\
& <\frac{1}{s},
\end{aligned}
$$

and by (2.1) for all $x, y \in X$, it follows that

$$
\begin{aligned}
d\left(T^{n_{0}} \chi, T^{n_{0}} y\right) & =d\left(T\left(T^{n_{0}-1} \chi\right), T\left(T^{n_{0}-1} y\right)\right) \\
& \preceq k d\left(T^{n_{0}-1} \chi, T^{n_{0}-1} y\right) \\
& =k d\left(T\left(T^{n_{0}-2} \chi\right), T\left(T^{n_{0}-2} y\right)\right) \\
& \preceq k^{2} d\left(T^{n_{0}-2} \chi, T^{n_{0}-2} y\right) \\
& \vdots \\
& \preceq k^{n_{0}} d(x, y) .
\end{aligned}
$$

Then by Case 1, we claim that the mapping $T^{n_{0}}$ has a unique fixed point $x^{* *} \in X$.

Now we prove that $x^{* *}$ is also a fixed point of $T$. As a matter of fact, on account of $T^{n_{0}} \chi^{* *}=\chi^{* *}$, we have

$$
\mathrm{T}^{\mathrm{n}_{0}}\left(\mathrm{~T} \chi^{* *}\right)=\mathrm{T}^{\mathrm{n}_{0}+1} \chi^{* *}=\mathrm{T}\left(\mathrm{T}^{\mathrm{n}_{0}} \chi^{* *}\right)=\mathrm{T} \chi^{* *},
$$

then $T x^{* *}$ is also a fixed point of $\mathrm{T}^{\mathrm{n}_{0}}$. Thus, by the uniqueness of fixed point of $\mathrm{T}^{\mathrm{n}_{0}}$, it ensures us that $\mathrm{T} x^{* *}=x^{* *}$. In other words, $x^{* *}$ is also a fixed point of $\mathrm{T}$.

Finally, we show that the fixed point of $T$ is unique. Virtually, we suppose for absurd that there exists another fixed point $x^{* * *}$ of $\mathrm{T}$, that is, $\mathrm{T} x^{* *}=x^{* *}, \mathrm{~T} x^{* * *}=x^{* * *}$, then

$$
\begin{aligned}
\mathrm{T}^{\mathrm{n}_{0}} \chi^{* *} & =\mathrm{T}^{\mathrm{n}_{0}-1}\left(\mathrm{~T} x^{* *}\right)=\mathrm{T}^{\mathrm{n}_{0}-1} \chi^{* *}=\cdots=\mathrm{T} x^{* *}=x^{* *}, \\
\mathrm{~T}^{\mathrm{n}_{0}} \chi^{* * *} & =\mathrm{T}^{\mathrm{n}_{0}-1}\left(\mathrm{~T} x^{* * *}\right)=\mathrm{T}^{\mathrm{n}_{0}-1} \chi^{* * *}=\cdots=\mathrm{T} x^{* * *}=x^{* * *},
\end{aligned}
$$

which imply that $x^{* *}$ and $x^{* * *}$ are two fixed points of $T^{n_{0}}$. Because the fixed point of $T^{n_{0}}$ is unique, we claim that $x^{* *}=x^{* * *}$.

Case 3: $s=1$. Since $\rho(k)<1$, repeat the process of Case 1 , then the claim holds.

Corollary 2.2. Let $(\mathrm{X}, \mathrm{d})$ be a $\mathrm{b}$-complete cone $\mathrm{b}$-metric space with coefficient $\mathrm{s} \geqslant 1$. Suppose that $\mathrm{T}: \mathrm{X} \rightarrow \mathrm{X}$ is a mapping such that for all $x, y \in X$, it holds:

$$
d(T x, T y) \preceq k d(x, y),
$$

where $\mathrm{k} \in[0,1)$ is a real constant. Then $\mathrm{T}$ has a unique fixed point in $\mathrm{X}$. And for any $\mathrm{x} \in \mathrm{X}$, the iterative sequence $\left\{T^{n} x\right\}(n \in \mathbb{N})$ b-converges to the fixed point.

Proof. Choose $k \in \mathbb{R}$ in Theorem 2.1, then the proof is completed.

Corollary 2.3. Let $(\mathrm{X}, \mathrm{d})$ be $a \mathrm{~b}$-complete $\mathrm{b}$-metric space with coefficient $\mathrm{s} \geqslant 1$. Suppose that $\mathrm{T}: \mathrm{X} \rightarrow \mathrm{X}$ is a mapping such that for all $\mathrm{x}, \mathrm{y} \in \mathrm{X}$, it holds:

$$
d(T x, T y) \leqslant k d(x, y),
$$

where $\mathrm{k} \in[0,1)$ is a real constant. Then $\mathrm{T}$ has a unique fixed point in $\mathrm{X}$. And for any $\mathrm{x} \in \mathrm{X}$, the iterative sequence $\left\{T^{n} x\right\}(n \in \mathbb{N})$ b-converges to the fixed point. 
Remark 2.4. Theorem 2.1 greatly generalizes [7, Theorem 2.1] from $\rho(k) \in\left[0, \frac{1}{s}\right)$ to $\rho(k) \in[0,1)$. Corollary 2.2 greatly generalizes [8, Theorem 2.1] from $k \in\left[0, \frac{1}{s}\right)$ to $k \in[0,1)$. Corollary 2.3 greatly generalizes [10, Theorem 3.3] from $k \in\left[0, \frac{1}{s}\right)$ to $k \in[0,1)$.

Remark 2.5. Regarding the improvement of contractive coefficients, there have been some articles dealing with them. For instance, compared with [11], [5] generalizes the range of the coefficient $\lambda$ from $\lambda \in\left(0, \frac{1}{2}\right)$ to $\lambda \in(0,1)$ for quasi-contraction, which is an interesting generalization. Whereas, our results generalize some famous results on Banach-type contractions for the coefficient $k$ from $\rho(k) \in\left[0, \frac{1}{s}\right)$ to $\rho(k) \in[0,1)$, as well as from $k \in\left[0, \frac{1}{s}\right)$ to $k \in[0,1)$. Consequently, our generalizations are indeed sharp generalizations. The following examples illustrate our conclusions.

Example 2.6. Let $X=[0,1], \mathbb{A}=C_{\mathbb{R}}^{1}(X)$ and define a norm on $\mathbb{A}$ by $\|u\|=\|u\|_{\infty}+\left\|u^{\prime}\right\|_{\infty}$. Define multiplication in $\mathbb{A}$ as just pointwise multiplication. Then $\mathbb{A}$ is a real Banach algebra with a unit $e=$ $1(e(t)=1$ for all $t \in X)$. The set $P=\{u \in \mathbb{A}: u(t) \geqslant 0, t \in X\}$ is a non-normal solid cone (see [9]). Define a mapping $d: X \times X \rightarrow \mathbb{A}$ by $d(x, y)(t)=|x-y|^{2} e^{t}$. We have that $(X, d)$ is a $b$-complete cone $b$ metric space over Banach algebra $\mathbb{A}$ with coefficient $s=2$. Define a self-mapping $T$ on $X$ by $T x=\frac{\sqrt{2}}{2} x$. Put $k=\frac{1}{2}+\frac{1}{4} \mathrm{t}$. Then $\mathrm{d}(\mathrm{T} x, \mathrm{Ty}) \preceq \mathrm{kd}(\mathrm{x}, \mathrm{y})$ for all $x, y \in X$. Simple calculations show that $\frac{1}{s}=\frac{1}{2}<\rho(k)=\frac{3}{4}<1$. Clearly, $\rho(k) \notin\left[0, \frac{1}{s}\right)$, but $\rho(k) \in\left[\frac{1}{s}, 1\right)$. Hence, [7, (i) of Theorem 2.1] is not satisfied. That is to say, [7, Theorem 2.1] cannot be used in this example. However, our Theorem 2.1 is satisfied. Accordingly, $\mathrm{T}$ has a unique fixed point $x=0$.

Example 2.7. Let $X=\left[0, \frac{3}{5}\right], E=\mathbb{R}^{2}$ and $p \geqslant 5$ be a constant. Put $P=\{(x, y) \in E: x, y \geqslant 0\}$. We define $d: X \times X \rightarrow E$ as $d(x, y)=|x-y|^{p}$, for all $x, y \in X$. Then $(X, d)$ is a b-complete b-metric space with coefficient $s=2^{p-1}$. Define a self-mapping $T$ on $X$ by $T x=\frac{1}{2}\left(\cos \frac{x}{2}-\left|x-\frac{1}{2}\right|\right)$, for all $x \in X$. Hence, for all $x, y \in X$, we speculate that

$$
\begin{aligned}
\mathrm{d}(\mathrm{T} x, \mathrm{Ty}) & =|\mathrm{T} x-T y|^{p} \\
& =\frac{1}{2^{p}}\left|\left(\cos \frac{x}{2}-\cos \frac{y}{2}\right)-\left(\left|x-\frac{1}{2}\right|-\left|y-\frac{1}{2}\right|\right)\right|^{p} \\
& \leqslant \frac{1}{2^{p}}\left(\left|\cos \frac{x}{2}-\cos \frac{y}{2}\right|+|x-y|\right)^{p} \\
& \leqslant \frac{1}{2^{p}}\left(\frac{|x+y|}{8}|x-y|+|x-y|\right)^{p} \\
& \leqslant 0.575^{p}|x-y|^{p} .
\end{aligned}
$$

In view of $p \geqslant 5$, then $k=0.575^{p} \notin\left[0, \frac{1}{s}\right)$, but $k=0.575^{p} \in\left[\frac{1}{s}, 1\right)$. Thus, [10, Theorem 3.3] does not hold in this case. In other words, [10, Theorem 3.3] is not applicable in this example. However, our Corollary 2.3 can be utilized in this case. To sum up, $x_{0} \in X$ satisfied with $0.472251591454<x_{0}<0.472251591479$ is the unique fixed point of $\mathrm{T}$.

\section{Acknowledgment}

The research was partially supported by the National Natural Science Foundation of China (11271045).

\section{References}

[1] I. A. Bakhtin, The contraction mapping principle in almost metric space, (Russian) Functional analysis, Ulyanovsk. Gos. Ped. Inst., Ulyanovsk, (1989), 26-37. 1, 1.1

[2] S. Banach, Sur les opérations dans les ensembles abstraits et leur application aux équations intégrales, Fund. Math., 3 (1922), 133-181. 1

[3] M. Boriceanu, M. Bota, A. Petruşel, Multivalued fractals in b-metric spaces, Cent. Eur. J. Math., 8 (2010), 367-377. 1

[4] S. Czerwik, Contraction mappings in b-metric spaces, Acta Math. Inform. Univ. Ostraviensis, 1 (1993), 5-11. 1, 1.1 
[5] L. Gajić, V. Rakočević, Quasi-contractions on a nonnormal cone metric space, Funct. Anal. Appl., 46 (2012), 62-65. 2.5

[6] H.-P. Huang, S. Radenović, Common fixed point theorems of generalized Lipschitz mappings in cone b-metric spaces over Banach algebras and applications, J. Nonlinear Sci. Appl., 8 (2015), 787-799. 1, 1.4, 1.8, 1.9

[7] H.-P. Huang, S. Radenović, Some fixed point results of generalized Lipschitz mappings on cone b-metric spaces over Banach algebras, J. Comput. Anal. Appl., 20 (2016), 566-583. 1, 1.3, 1, 1.6, 2.4, 2.6

[8] H.-P. Huang, S.-Y. Xu, Correction: Fixed point theorems of contractive mappings in cone b-metric spaces and applications, Fixed Point Theory Appl., 2014 (2014), 5 pages. 1, 2.4

[9] S. Janković, Z. Kadelburg, S. Radenović, On cone metric spaces: a survey, Nonlinear Anal., 74 (2011), 2591-2601. 1.7, 2.6

[10] M. Jovanović, Z. Kadelburg, S. Radenović, Common fixed point results in metric-type spaces, Fixed Point Theory Appl., 2010 (2015), 15 pages. 1, 1, 2.4, 2.7

[11] Z. Kadelburg, S. Radenović, V. Rakočević, Remarks on "Quasi-contraction on a cone metric space", Appl. Math. Lett., 22 (2009), 1674-1679. 2.5

[12] P. K. Mishra, S. Sachdeva, S. K. Banerjee, Some fixed point theorems in b-metric space, Turkish J. Anal. Number Theory, 2 (2014), 19-22. 1

[13] W. Sintunavarat, Fixed point results in b-metric spaces approach to the existence of a solution for nonlinear integral equations, ev. R. Acad. Cienc. Exactas Fs. Nat. Ser. A Math. RACSAM, 110 (2016), 585-600. 1

[14] W. Sintunavarat, Nonlinear integral equations with new admissibility types in b-metric spaces, J. Fixed Point Theory Appl., 18 (2016), 397-416.

[15] O. Yamaod, W. Sintunavarat, Y. J. Cho, Common fixed point theorems for generalized cyclic contraction pairs in b-metric spaces with applications, Fixed Point Theory Appl., 2015 (2015), 18 pages. 1

[16] O. Yamaod, W. Sintunavarat, Y. J. Cho, Existence of a common solution for a system of nonlinear integral equations via fixed point methods in b-metric spaces, Open Math., 14 (2016), 128-145. 1 